\title{
Correspondence
}

Epidemiol. Infect. (2014).

doi:10.1017/S0950268813001921

First published online 6 August 2013

\section{Prevalence of Trypanosoma cruzi infection in Latin American pregnant women and level of compliance of the Valencian Health Programme in the city of Alicante}

To the Editor

In the October 2012 issue of Epidemiology and Infection, Barona-Vilar et al. reported on the level of implementation of the protocol for early diagnosis of Chagas disease in pregnant Latin American women ('Valencian Health Programme in Latin American Immigrant Women') in the city of Valencia (Valencian Community, Spain) during 2009 and 2010 [1]. In 2007, the public health authorities in the Valencian Community decided to design and perform a strategy for dealing with the early diagnosis of Chagas disease in pregnant women from endemic countries $[2,3]$. We conducted a similar analysis of the level of compliance with the recommendations of the Valencian Health Programme in Latin American immigrant women living in the city of Alicante (Valencian Community, Spain). We performed a retrospective analysis from January 2008 to August 2012, crossing our records database of deliveries in Latin American women in the Department of Obstetrics in the hospital, with the database of Trypanosoma cruzi serology performed during the same period in the Section of Microbiology. The detection of antibodies was performed by one serological test (SD Chagas Ab Rapid, SD Standard Diagnostics Inc., Korea).

A total of 1132 pregnant women from Central and South America (excluding the Caribbean countries) were studied. The median age was 29.7 years (s.D. $=6 \cdot 3$ ). The serological test against $T$. cruzi during pregnancy was performed in 466 women [compliance rate of the programme: $41 \cdot 2 \%, 95 \%$ confidence interval (CI) 38.3-44.1]. During the first period, from January to August 2008, the serological test was performed in $27 \cdot 1 \%$ of pregnant women, after that the compliance rate of the programme was increased (Fig 1). The compliance rate was significantly higher in women from Bolivia (59.8\%), and Ecuador $(47.8 \%)$ than in women form Argentina (27.5\%) (Table 1).

The overall seroprevalence of $T$. cruzi was $3 \cdot 0 \%$ (14/466, 95\% CI 1·7-5.1). All T. cruzi-infected women were from countries of the Gran Chaco Region (Bolivia: 18.8\%, 95\% CI 10.3-31.8; Paraguay: $5 \cdot 4 \%$, 95\% CI 0.9-19.5; Argentina: $2 \cdot 9 \%$, $95 \%$ CI $0 \cdot 1-13$ ). If we considered the prevalence in women who had the serology performed, 20 Latin American pregnant women were not diagnosed (Table 1). The genome of $T$. cruzi amplified by PCR was performed in 11 women, and we received a positive result for eight $(72 \cdot 7 \%)$. The follow-up of newborns was available in 10 infants. They all had T. cruzi antibodies, but the genome amplification by PCR was negative for all of them.

Barona-Vilar et al. revealed that the compliance rate of the Valencian Health Programme in Latin American immigrant women was 95.4\% [1]. Our findings reveal that the prenatal care programme conducted by midwives was not as good as in the study by Barona-Vilar et al. There are two differences in the same programme: first, in the city of Valencia, in the case of control women, these serological tests were performed at the time of delivery in the hospital; in our study this was not done. Furthermore, in their study, the authors did not describe the percentage of serologies performed during delivery. Second, in the city of Valencia there were workshops for the midwives who motivated the women to allow $T$. cruzi serology; in our study we did not have these workshops. In another study performed in another city in the Valencian Community, Elche, the compliance rate of 
Table 1. Compliance rate of the recommendations of the Valencian Health Programme (VHP) in Latin American immigrant women and overall Trypanosoma cruzi seroprevalence by country and theoretical number of $\mathrm{T}$. cruzi-infected pregnant women non-diagnosis.

\begin{tabular}{|c|c|c|c|c|c|c|c|c|c|c|}
\hline & \multicolumn{2}{|c|}{$\begin{array}{l}\text { Pregnant } \\
\text { women } \\
\text { delivered }\end{array}$} & \multicolumn{2}{|c|}{$\begin{array}{l}\text { Pregnant } \\
\text { women with } \\
\text { serological test }\end{array}$} & \multirow{2}{*}{$\begin{array}{l}\text { OR }(95 \% \mathrm{CI}) \text { of } \\
\text { compliance rate } \\
\text { of VHP }\end{array}$} & \multirow{2}{*}{$\begin{array}{l}\text { No. } \\
\text { positive }\end{array}$} & \multirow{2}{*}{$\begin{array}{l}T . \text { cruzi } \\
\text { seroprevalence }\end{array}$} & \multirow{2}{*}{$\begin{array}{l}\text { OR }(95 \% \mathrm{CI}) \text { of } \\
\text { seroprevalence }\end{array}$} & \multicolumn{2}{|c|}{$\begin{array}{l}\text { Theoretical } \\
\text { pregnant women } \\
\text { non-diagnosed } \S\end{array}$} \\
\hline & $N$ & $\% *$ & $N$ & $\% \dagger$ & & & & & $N$ & Range \\
\hline Ecuador & 312 & $27 \cdot 6$ & 149 & $47 \cdot 8$ & $1 \cdot 45(1 \cdot 12-1 \cdot 89)$ & 0 & $0 \cdot 0$ & $(0-3 \cdot 1)$ & 0 & $(0-5)$ \\
\hline Colombia & 264 & $23 \cdot 3$ & 112 & $42 \cdot 4$ & $1 \cdot 07(0 \cdot 81-1 \cdot 41)$ & 0 & $0 \cdot 0$ & $(0-4 \cdot 1)$ & 0 & $(0-6)$ \\
\hline Argentina & 167 & $14 \cdot 8$ & 46 & $27 \cdot 5$ & $0 \cdot 50(0 \cdot 37-0 \cdot 77)$ & 1 & $2 \cdot 2$ & $(0 \cdot 1-13)$ & 4 & $(0-16)$ \\
\hline Bolivia & 97 & $8 \cdot 6$ & 57 & $58 \cdot 8$ & $2 \cdot 30(1 \cdot 51-3 \cdot 49)$ & 11 & $18 \cdot 8$ & $(10 \cdot 3-31 \cdot 8)$ & 8 & $(4-12)$ \\
\hline Paraguay & 82 & $7 \cdot 2$ & 37 & $45 \cdot 1$ & $1 \cdot 19(0 \cdot 76-1 \cdot 73)$ & 2 & $5 \cdot 4$ & $(0 \cdot 9-19 \cdot 5)$ & 3 & $(0-9)$ \\
\hline Venezuela & 51 & $4 \cdot 5$ & 14 & $27 \cdot 5$ & $0 \cdot 51(0 \cdot 27-0 \cdot 95)$ & 0 & $0 \cdot 0$ & $(0-26 \cdot 8)$ & 0 & $(0-10)$ \\
\hline Brazil & 39 & $3 \cdot 4$ & 12 & $30 \cdot 8$ & $0 \cdot 59(0 \cdot 31-1 \cdot 19)$ & 0 & $0 \cdot 0$ & $(0-30 \cdot 1)$ & 0 & $(0-8)$ \\
\hline Uruguay & 39 & $3 \cdot 4$ & 10 & $25 \cdot 6$ & $0.46(0 \cdot 22-0 \cdot 96)$ & 0 & $0 \cdot 0$ & $(0-34 \cdot 5)$ & 0 & $(0-10)$ \\
\hline Peru & 38 & $3 \cdot 3$ & 15 & $39 \cdot 5$ & $0 \cdot 87(0.45-1.69)$ & 0 & $0 \cdot 0$ & $(0-25 \cdot 4)$ & 0 & $(0-6)$ \\
\hline Others $\|$ & 43 & $3 \cdot 8$ & 13 & $30 \cdot 2$ & - & 0 & $0 \cdot 0$ & $(0-28 \cdot 3)$ & 5 & $(0-9)$ \\
\hline Total & 1132 & 100 & 465 & $41 \cdot 1$ & - & 14 & $3 \cdot 0$ & $(1 \cdot 7-5 \cdot 1)$ & 20 & $(11-34)$ \\
\hline
\end{tabular}

OR, Odds ratio; CI, confidence interval.

* Percentage of pregnant women delivered.

$\dagger$ Percentage of origin (compliance rate of VHP).

+ As reference others nationalities.

$\S$ Theoretical pregnant women non diagnosed $=$ number of pregnant women in who the serological test were not performed $\times$ prevalence of positive case.

|| Other countries (total/performed/\%): Chile (14/5/35·7); Honduras (11/5/45·5); Mexico (6/2/33.3); Costa Rica (4/0/0); El Salvador (3/1/33·3); Guatemala (2/0/0); Surinam $(2 / 0 / 0)$; Nicaragua $(1 / 0 / 0)$. 


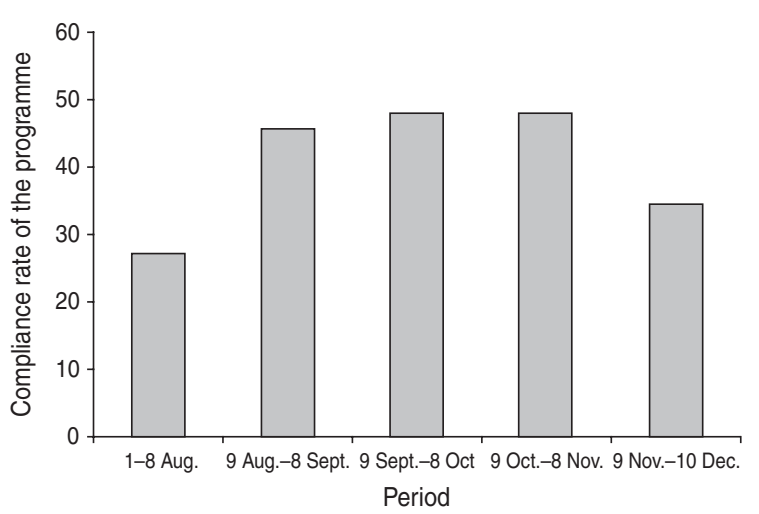

Fig. 1. Compliance rate of the recommendations of the Valencian Health Programme in Latin American immigrant women from January 2008 to September 2012.

the Valencian Health Programme was $40 \%$, but in this case they also preformed the test at the time of delivery [4]. In the city of Alicante we need to implement some of the strategies of Barona-Vilar et al., specifically the midwives' workshop and serology performed at the time of delivery. In Catalonia in the Screening Programme of Chagas Disease in Newborns of Latin American origin, the rate of coverage in 2010 was $77 \cdot 7 \%$ [5]. Our study was similar to others performed in Spain where the higher prevalence of T. cruzi infection (over $80 \%$ ) was found in pregnant Bolivian women $[1,4,5,6]$.

In conclusion, we recommend implementation of screening in other areas of Spain. Moreover, it is important to perform screening on pregnant woman in other European countries where there is Latin American immigration especially from Bolivia. Possibly, the Valencian and Catalonian programmes should be mirrored in any country with Latin American immigrants.

\section{Declaration of Interest}

None.

\section{References}

1. Barona-Vilar C, et al. Prevalence of Trypanosoma cruzi infection in pregnant Latin American women and congenital transmission rate in a non-endemic area: the experience of the Valencian Health Programme (Spain). Epidemiolology and Infection 2012; 140: 18961903.

2. Generalitat Valenciana. Imported Chagas disease. Protocol of actions in the Valencian Community [in Spanish]. Valencia: Generalitat Valenciana, Conselleria de Sanitat, 2009, pp. 65 (http://publicaciones.san.gva.es/
publicaciones/documentos/V-5243-2008.pdf). Accessed 10 July 2013.

3. Generalitat Valenciana. Control regulation of congenital and perinatal infections in Valencia Community [in Spanish]. Valencia: Generalitat Valenciana, Conselleria de Sanitat, 2007, pp. 57 (http://www.sp.san.gva. es/DgspPortal/docs/CIRCULAR_3_2007.pdf). Accessed 23 September 2012.

4. Ramos-Rincón JM, et al. Evaluation of the grade of application of the recommendations of screening for Chagas disease in pregnant women. Revista Clinica Española 2012; 212: 366-368.

5. Basile $\mathbf{L}$, Ciruela $\mathbf{P}$, and the work group of Chagas disease in Catalonia. Update of the screening program of Chagas diseases in newborns of Latin American origin in Catalonia. Revista Española de Salud Publica 2013; 87: 51-52.

6. Flores-Chavez MD, et al. Surveillance of Chagas disease in pregnant women in Madrid, Spain, from 2008 to 2010. Eurosurveillance 2011; 16: pii $=19974$.

J. M. RAMOS ${ }^{1,2, *}$, H. PINARGOTE ${ }^{1}, M \cdot \operatorname{ANDREU}^{3}$,

J. SASTRE ${ }^{4}$, D. TORRUS ${ }^{5}$, J. C. MARTINEZ-ESCORIZA ${ }^{2,6}$, J. PORTILLA ${ }^{1,2,5}$

${ }^{1}$ Department of Internal Medicine, Hospital General

Universitario de Alicante, Alicante, Spain

${ }^{2}$ Universidad Miguel Hernández, Campus de San Juan, Alicante, Spain

${ }^{3}$ Section of Microbiology, Hospital General Universitario de Alicante, Alicante, Spain

${ }^{4}$ Unit of Admission and Documentation, Hospital General Universitario de Alicante, Alicante, Spain

${ }^{5}$ Unit of Infectious Diseases, Hospital General Universitario de Alicante, Alicante, Spain

${ }^{6}$ Department of Gynecology and Obstetrics, Hospital General Universitario de Alicante, Alicante, Spain

*Author for correspondence:

J. M. Ramos, Department of Internal Medicine, Hospital General Universitario de Alicante, C/ Pintor Baeza, 12, 03010 Alicante, Spain.

(Email: jramosrincon@yahoo.es)

Epidemiol. Infect. (2014).

doi:10.1017/S0950268813001933

First published online 6 August 2013

\section{Prevalence of Trypanosoma cruzi infection in Latin} American pregnant women and level of compliance of the Valencian Health Programme in the city of Alicante: a reply

The study of Ramos et al. [1] above, describes the coverage of Chagas disease screening in pregnant women from endemic countries living in Alicante. Their results were compared to our study showing results 